ORIGINAL RESEARCH PAPER

\title{
INFLUENCE OF OAT FLOUR ON PASTING PROPERTIES OF FLOUR BLENDS, COOKING QUALITY AND SENSORY ATTRIBUTES OF VERMICELLI
}

\author{
AKANKSHA PAHWA*, KAUSHIK KHAMRUI, WRITDHAMA PRASAD \\ Dairy Technology Division, ICAR - National Dairy Research Institute, Karnal 132001, Haryana, India \\ "corresponding author: akankshapahwa91@gmail.com
}

Received on 15 July 2020

Revised on 20 October 2020

\begin{abstract}
Supplementation of oat flour into vermicelli may improve the nutritional quality, but textural and sensory attributes should not be adversely affected. The present study was carried out with the aim to evaluate the influence of oat flour substitution on functional and pasting properties of flour formulations, and the sensory and cooking quality of wheat-semolina based vermicelli. Different ratios viz. 50:50, 33:66, 25:75, 66:33, 40:60, 75:25 and 60:40 of durum wheat and oat flour were tried, and corn flour $\sim 15 \%$ was added to the wheat semolina and oat flour mix, and afterwards the extruded wet vermicelli was fluidized bed dried at $90^{\circ} \mathrm{C}$. Statistically significant variations were observed for the pasting properties of different flour blends. Increasing the oat flour concentration led to a significant decrease in cooking quality in terms of swelling index, water holding capacity and cooking losses. The overall acceptability of formulation having 50\% oat, $50 \%$ wheat semolina and $15 \%$ corn flour was similar to the control vermicelli prepared from wheat semolina. Thus, up to $50 \%$ replacement of wheat semolina by oat flour produced vermicelli with acceptable sensory and cooking quality, which could be recommended for the preparation of $\beta$-glucan enriched vermicelli without compromising its quality attributes.
\end{abstract}

Keywords: oat flour, vermicelli, cooking quality, sensory properties, pasting properties

\section{Introduction}

In recent years oat has enjoyed wide applications in the food industry due to its superior nutritional value as compared to other cereals. Oat grain is the richest source of both soluble and insoluble dietary fibre (Pilli et al., 2013). Oat possesses many physiological benefits, like reducing hyperglycaemia, hyperinsulinaemia and hypercholesterolemia, due to the presence of a significant amount of water-soluble

https://doi.org/10.35219/foodtechnology.2020.2.05 
$(1 \rightarrow 4)$ - $\beta$-glucan). Most common food applications of oat include consumption as porridge or as an ingredient in cakes, cookies and bread (Pilli et al., 2013).

Vermicelli is a traditional product of Italy, prepared primarily from whole or refined hard wheat flour, followed by cold extrusion and drying (Sowbhagya and Zakiuddin Ali, 2001; Shobha et al., 2015). Vermicelli is used extensively in various regional cuisines across the world. Besides cooked with milk to form kheer, vermicelli can also be cooked in ghee to prepare a dried version of vermicelli sweet dish, garnished with herbs and spices to prepare dishes like upma, and as side dishes like soup and salads. Vermicelli is also used to prepare falooda, a frozen dessert in which vermicelli is served with kulfi. Desirable appearancerelated quality attributes of vermicelli are uniform colour, and the absence of sticky surface (Sowbhagya and Zakiuddin Ali, 2001). As regards cooking quality, maintenance of integrity, increase in the volume of strands and minimal exudate into cooking water are the most important characteristics (Sowbhagya and Zakiuddin Ali, 2001).

Oat has recently attracted attention from research and commere alike, mainly due to its multifunctional attributes, which may also improve the nutritional value of vermicelli. Limited replacement of durum wheat semolina by oat flour resulted in nutritionally superior short pasta due to higher protein, dietary fiber, and total $\beta$ glucan content (Aydin and Gocmen, 2011).

The challenges of incorporating oat flour into conventional pasta are that it could alter its sensory, cooking and colour values to an undesirable extent (Pilli et al., 2013). Oat flour added to wheat flour formulations imparts a softer, stickier and less elastic texture to vermicelli, due to the lack of gluten-forming proteins that provide structure and viscoelasticity (Majzoobi et al., 2014). The colour of dried oat flour noodles became darker with the inclusion of oat flour (Aydin and Gocmen, 2011). Moreover, the cooking quality of oat-based vermicelli is compromised by susceptibility to breakage and the colour of dried oat flour noodles became darker with the inclusion of more than $20 \%$ oat flour (Majzoobi et al., 2014). Studies showed that pasta products enriched with increased oat flour levels involved an extension of optimum cooking time and caused greater cooking loss (Pilli et al., 2013).

Starches are widely used in the food industry to impart texture and stability to the product. Corn starch is a commercial ingredient for food industries and is used as a thickener, gelling agent, bulking agent and water retention agent (Chandla et al., 2017). The addition of starches and their derivatives from different sources to flour improves the cooking and eating qualities of vermicelli. The major quality factors that govern the characteristics of corn starch in vermicelli are cooked weight, cooking loss and textural properties. The physico-chemical, morphological and rheological properties of corn starch affect the vermicelli manufacturing properties (Chandla et al., 2017).

The objective of the present study was to evaluate the influence of oat flour substitution on the pasting, sensory and cooking quality of wheat-semolina based vermicelli. 


\section{Materials and methods}

\section{Materials}

Wheat semolina, oat flakes and corn flour were purchased from the local market of Karnal, Haryana (India). Oat flour was produced by grinding oat flakes into flour. The flours were sifted using a sieve (mesh size: $1000 \mu \mathrm{m}$ ) before use.

\section{Vermicelli preparation}

Vermicelli was prepared with different ratio of wheat semolina and oat flour such as 50:50, 33:66, 25:75, 66:33, 40:60, 75:25 and 60:40, corresponding to 1:1, 1:2, $1: 3,2: 1,2: 3,3: 1$ and $3: 2$ ratios, respectively, keeping the quantity of corn flour constant at $15 \%$ of mixture of wheat semolina and oat flour (Table 1). After preliminary trials of blending corn flour at a 10,15,20\% rate, it was observed that corn flour blending at a $10 \%$ rate produced vermicelli with high toughness and broken vermicelli. Furthermore, corn flour blending at a $15 \%$ rate resulted in optimum sensorial quality characteristics in vermicelli, like elasticity, chewiness, toughness and integrity. Corn flour blending at a $20 \%$ rate resulted in vermicelli with low toughness, less chewiness and sticky texture. Therefore, corn flour blending at a $15 \%$ rate was selected to prepare oat-semolina based vermicelli.

The ingredients (wheat semolina, oat flour, corn flour and water) were mixed in the mixing chamber of the pasta making machine (LB Italia SRL, Mozzate CO, Italy) to get proper dough consistency. After mixing for 15 to $20 \mathrm{~min}$, the cold dough was extruded at $40{ }^{\circ} \mathrm{C}$ through a vermicelli die. The wet vermicelli strands were then dried in a fluidized bed drier (Model SMST, M/s SM Scientech, Calcutta) at $90{ }^{\circ} \mathrm{C}$ until the moisture content in the strands ranged between $7 \pm 2 \%$.

Table 1. Vermicelli formulations with different ratios of oat flour and wheat semolina.

\begin{tabular}{cccccccc}
\hline S.No. & $\mathbf{T}_{\mathbf{1}}$ & $\mathbf{T}_{\mathbf{2}}$ & $\mathbf{T}_{\mathbf{3}}$ & $\mathbf{T}_{\mathbf{4}}$ & $\mathbf{T}_{\mathbf{5}}$ & $\mathbf{T}_{\mathbf{6}}$ & $\mathbf{T}_{\mathbf{7}}$ \\
\hline Wheat Semolina (parts) & 50 & 33 & 25 & 66 & 40 & 75 & 60 \\
Oat flour (parts) & 50 & 66 & 75 & 33 & 60 & 25 & 40 \\
Drying temperature $\left({ }^{\circ} \mathbf{C}\right)$ & 90 & 90 & 90 & 90 & 90 & 90 & 90 \\
Time of kneading $(\mathbf{s e c})$ & 620 & 780 & 900 & 614 & 614 & 600 & 780 \\
Quantity of water (ml) & 380 & 470 & 510 & 360 & 430 & 340 & 365 \\
Weight of wet vermicelli (g) & 1481 & 1611 & 1690 & 1488 & 1578 & 1489 & 1499 \\
Drying time (min) & 30 & 40 & 25 & 25 & 25 & 30 & 25 \\
\hline
\end{tabular}

* Corn flour was added at the rate $15 \%$ of the mix

\section{Chemical attributes of raw material and oat-semolina based vermicelli}

AACC (2000) methods were followed to determine the moisture (method 05-02) and ash content (method 08-01) of the ingredients and vermicelli samples. AOAC (2000) methods were used to determine the fat (method 30-25) and protein content (method 46-12) of the ingredients and vermicelli samples. $\beta$-glucan was estimated enzymatically using a $\beta$-glucan assay kit (method 32-33) (K-BGLU 05/15, MegazymeCo., Wicklow, Ireland) (AOAC, 2000). 


\section{Functional Properties}

Water absorption index (WAI) and fat absorption capacities (FAC)

The water absorption index (WAI) and fat absorption capacity (FAC) were measured according to Bhise et al. (2015) method.

\section{Pasting properties}

A Rapid Visco Analyzer (RVA-4) (Newport Scientific Pvt. Ltd., Warrie-wood, Australia) was used to determine the pasting properties of blends using the method described by Kaur et al. (2010).

\section{Cooking quality of vermicelli}

The optimum cooking time of the oat-semolina based vermicelli samples was determined according to Shobha et al. (2015). The cooking loss of the vermicelli samples was determined according to the method prescribed by BIS (1993). The water holding capacity (WHC) of the dry vermicelli was calculated according to Deshpande and Poshadri (2011). The swelling index (SI) was determined as the percentage difference in the volume of cooked and uncooked vermicelli Bhise et al. (2015).

\section{Sensory analysis of oat-semolina based vermicelli}

The sensory evaluation of the oat-semolina based vermicelli was performed with an semi-trained evaluation panel consisting of 10 members. The attributes were quantified by means of an intensity rating scale from 0 to 10 , where 0 means that a particular attribute has very low intensity rating and 10 means that a particular attribute corresponded to very high liking intensity. The overall quality rating was measured using a scale from 1 to 10 , where $<6$ was considered 'poor', 6 to 7 'fair' and 8 to 10 'good'. The samples were served monadically with deionized water. The descriptors used in the sensory evaluation were appearance, starch mouth coating, bulkiness, grittiness, cohesiveness, chewiness, firmness, and overall acceptability (Shogren et al., 2006).

\section{Statistical analyses}

Statistical analyses were carried out using (SPSS Inc, Chicago, USA, version 20.0). A one-way analysis of variance was carried out using completely randomized design, and means were compared using Duncan's Multiple Range Test at $5 \%$ level of significance. The results are presented as means \pm S.E. (standard error) from triplicate analyses.

\section{Results and discussion}

\section{Chemical composition of raw materials and vermicelli}

The chemical composition of raw materials used in the present study is shown in Table 2. Wheat semolina flour had $10.29 \%$ moisture, $9.01 \%$ protein, $1.37 \%$ fat, $0.46 \%$ ash and $0.39 \% \beta$-glucan. The compositional parameters were in accordance with the values reported earlier. Brown (2014) reported that protein content in durum wheat semolina ranges from 9 to $18 \%$. The fat content in different varieties of durum wheat semolina was reported to vary from 1.11 to 1.60 
$\%$ (Rayas-Duarte et al., 1996). Sudha et al. (2007) reported ash content in durum wheat to be $0.45 \%$. $\beta$-glucan in wheat flour was found in line with the range reported by Havrlentova et al. (2011). Oat flour had $6.88 \%$ moisture, $10.12 \%$ protein, $8.11 \%$ fat, $1.1 \%$ ash and $4.70 \% \beta$-glucan (Table 2). Salehifar and Shahedi (2010) reported that moisture content in oat flour to be $5.61 \%$. Gulvady et al. (2013) reported 10.6-22.6 \% protein content in Canadian oats. Zhou et al. (1998) reported the lipid content in oat cultivars to vary from 5-10\%. The ash content of roller dried oat was reported to be $1.14 \%$ (Oomah, 1983). Corn flour contained $9.00 \%$ protein, $4.05 \%$ moisture, $3.80 \%$ fat, $0.71 \%$ ash and $0.02 \% \beta$ glucan (Table 2). The protein and fat content of corn flour was similar to those obtained for traditional as well as commercial nixtamalized corn flour investigated earlier (Palacios-Fonseca et al., 2009), which contained 8.34-9.64 \% protein and $3.89-4.88 \%$ fat. Sandhu et al. (2007) reported 0.19-1.66 \% ash content in corn varieties. Manley (2011) reported the moisture content in corn flour to be up to 5 $\%$.

The average chemical composition of vermicelli supplemented with oat flour, dried at $90{ }^{\circ} \mathrm{C}$ is seen in Table 3. The addition of oat flour significantly $(\mathrm{p}<0.05)$ increased the protein, fat, ash and $\beta$-glucan content of vermicelli. The samples of vermicelli having $75 \%$ oat flour contained significantly $(\mathrm{p}<0.05)$ higher protein, fat, ash and $\beta$-glucan content than solely durum wheat-based vermicelli. This could be attributed to the higher protein, fat, ash and $\beta$-glucan content in oat flour as compared to wheat and corn flour (Table 2).

Table 2. Chemical characterization of raw material.

\begin{tabular}{cccc}
\hline Flour Characteristics & Wheat semolina & Oat flour & Corn flour \\
\hline Moisture (\%) & $10.29 \pm 0.05$ & $6.88 \pm 0.04$ & $4.05 \pm 0.04$ \\
Protein (\%) (dwb) & $9.01 \pm 0.08$ & $10.12 \pm 0.06$ & $9.00 \pm 0.46$ \\
Fat (\%) (dwb) & $1.37 \pm 0.03$ & $8.11 \pm 0.07$ & $3.80 \pm 0.17$ \\
Ash (\%) (dwb) & $0.46 \pm 0.02$ & $1.10 \pm 0.22$ & $0.71 \pm 0.02$ \\
p-glucan (\%) (dwb) & $0.39 \pm 0.005$ & $4.70 \pm 0.06$ & $0.02 \pm 0.006$ \\
Carbohydrates (\%) (dwb)* & $78.49 \pm 0.04$ & $69.09 \pm 0.16$ & $82.42 \pm 0.37$ \\
\hline
\end{tabular}

Each value is expressed as mean $\pm \mathrm{SE}$ ( $\mathrm{n}$ is equal to 3 ). * determined by difference

\section{Functional properties of flours and blend flours}

Water absorption index (WAI)

The water absorption index (WAI) is the ability of flour to absorb water and swell, which is an indicator of yield and consistency characteristics in vermicelli (Choi et $a l ., 2012)$. Corn flour exhibited the highest value $(2.04 \mathrm{~g} / \mathrm{g})$ of WAI, whereas wheat semolina showed the lowest WAI $(0.83 \mathrm{~g} / \mathrm{g})$ as shown in (Table 4$)$. The capacity of water absorption increased significantly $(\mathrm{p}<0.05)$ as the level of oat flour increased in the blend flour. This means oat flour swells easily, providing greater viscosity. 


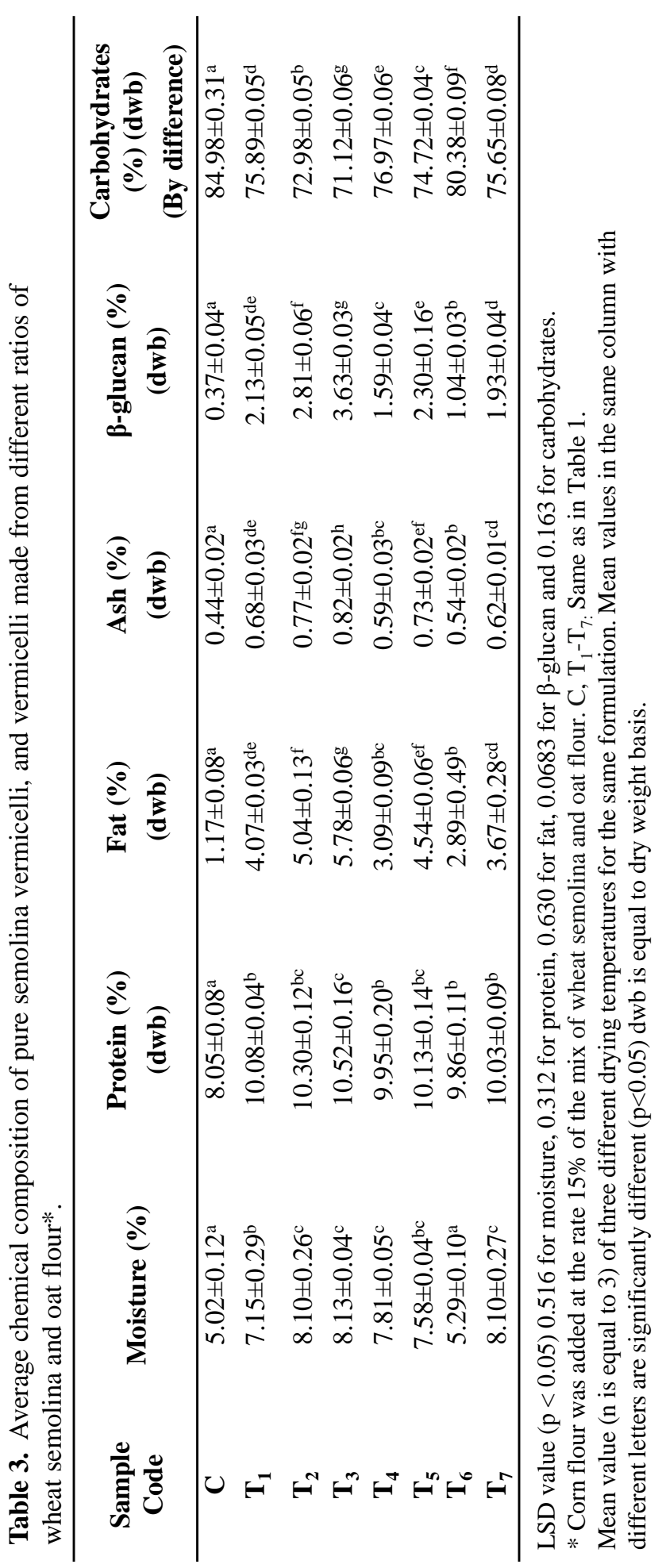




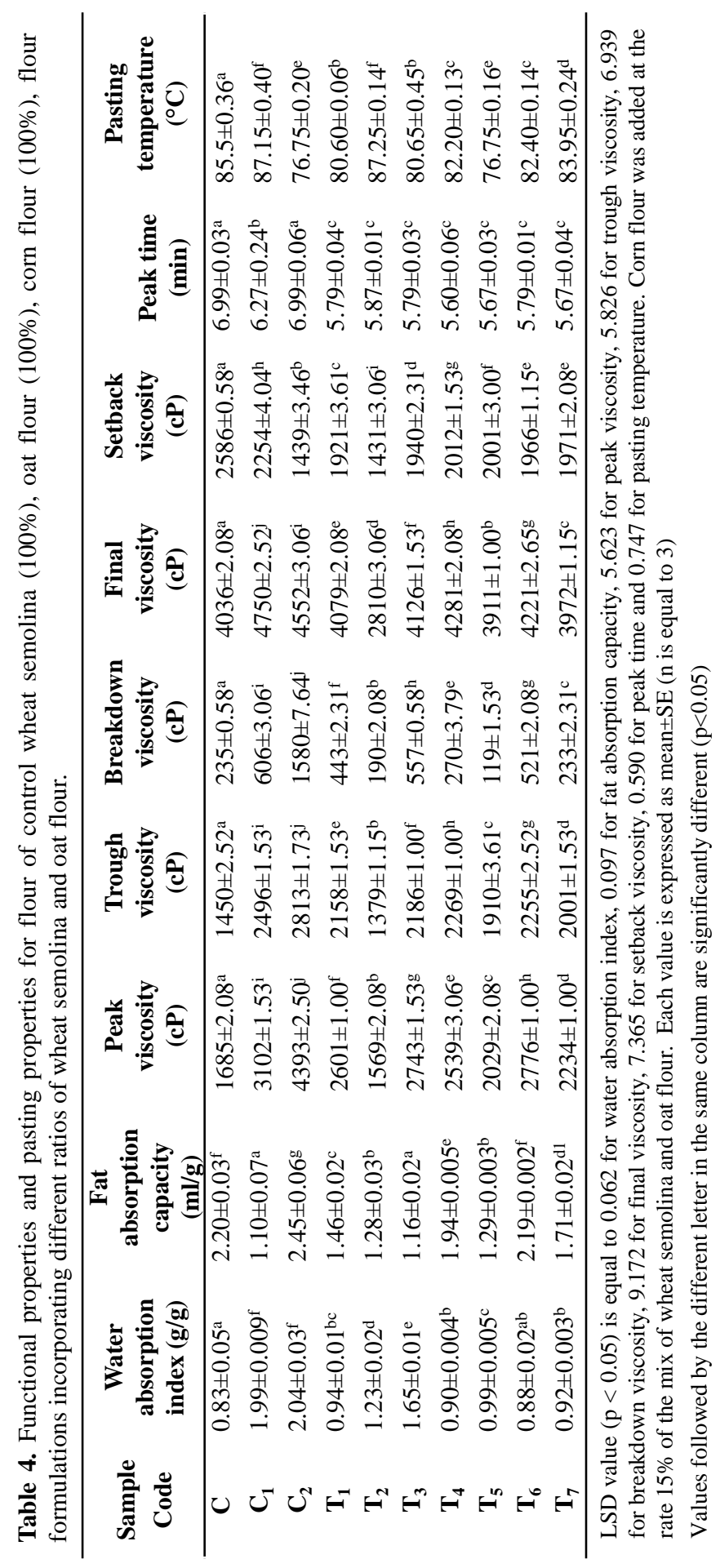


Choi et al. (2012) reported that increased WAI could be attributed to the $\beta$-glucan content. Also, differences in water absorption might be related to differences in chemical and protein composition, degree of starch damage and gelatinization and particle size distribution among the samples (Choi et al., 2012). The higher WAI of oat flour could be due to the steam treatment which was provided during the manufacture of oat flakes from oat groats (Oomah, 1983).

\section{Fat Absorption Capacity (FAC)}

Fat Absorption Capacity (FAC) involves the physical mechanism of capturing oil by the capillary action of the porous structure of the samples. It is another important functional property, as it improves the mouth feel and retains the flavour (Yadav et al., 2014). Corn flour showed the highest $(2.45 \mathrm{ml} / \mathrm{g}$ ) value for FAC, whereas oat flour showed the lowest FAC $(1.10 \mathrm{ml} / \mathrm{g})$, as shown in (Table 4). The capacity of fat absorption decreased significantly $(p<0.05)$ as the level of oat flour increased in the composite flour. This could be due to the $\beta$-glucan present in oat flour which has high water-holding capacity and viscosity development and is thus helpful in reducing the oil uptake (Sudha et al., 2012).

\section{Pasting properties of flours and flour blends}

The pasting properties, viz. PV (peak viscosity), TV (trough viscosity), BDV (breakdown viscosity), FV (final viscosity), and SBV (setback viscosity) that gives an indication of the cooking behaviour for various treatments, are shown in (Table 4). The peak viscosity occurred at the equilibrium point between swelling and polymer leaching which caused an increase in viscosity. It also indicated the waterbinding capacity of the starch or mixture (Kaur et al., 2010). The peak viscosity was found to be significantly higher $(\mathrm{p}<0.05)$ for corn flour $(4393 \mathrm{cP})$, followed by oat flour $(3102 \mathrm{cP})$, wheat semolina-oat flour blends, and the lowest value was found for wheat semolina $(1685 \mathrm{cP})$. The exudation of proteins and lipids from corn starch granules during the alkali treatment of corn starch could have led to the rapid swelling of granules and thus, the highest peak viscosity (Nadiha et al., 2010). Furthermore, the higher peak viscosity of oat flour could be due to the steam treatment which was applied during the manufacture of oat flakes from oat groats, which might have led to increase in the formation of mucilaginous compounds, thereby resulting into increased viscosity (Oomah, 1983). The viscosity pattern of oat and corn flour pastes showed that the oat flour tended to have a lower peak viscosity than corn flour. This may be due to larger quantities of starch lipid in the oat flour, as described by Wang and White (1994).

The breakdown of viscosity is caused by the rupture of swollen granules. The lower value of breakdown indicated lesser capacity to hold water (Kaur et al., 2010). The breakdown viscosity for oat flour was significantly higher $(606 \mathrm{cP})$ than that of the durum wheat $(235 \mathrm{cP})$ and wheat semolina-oat flour blends. This may be due to the fact that higher breakdown values are associated with peak viscosities, which, in turn, are related to the degree of swelling of the starch granules during heating (Kaur et al., 2010). Moreover, the greater breakdown of alkali treated corn flour indicated weaker granular structure and a greater tendency to lose viscosity upon holding and shearing. The results are in line with those reported by Nadiha et al. (2010), who stated that the 
reduction in amylose and protein contents of alkali treated corn starch could have rendered the granules more prone to rupture.

The final viscosity indicated the ability of the material to form a viscous paste or gel after cooking and cooling. The gel formed at the end of the RVA cooling cycle is essentially a three-dimensional network of intertwined amylose molecules incorporating dispersed swollen and ruptured starch granules (Kaur et al., 2010). The final viscosity was significantly $(\mathrm{p}<0.05)$ higher for pure oat flour $(4750 \mathrm{cP})$ as compared with other flour formulations. The results are in agreement with the findings of Zhou et al. (1998), who reported that final viscosity was higher for all oat flours compared, which could be due to the fact that the stronger internal structural network of the hot oat flour pastes is magnified by cooling (Zhou et al., 1998).

During setback, the mixture is cooled and re-association takes place between the starch granules, which results in gel structure formation and increase in viscosity due to retrogradation. Oat flour is reported to exhibit a lower degree of retrogradation than wheat semolina, due to the greater amount of internally bound lipids, which are one of the major factors in lowering retrogradation (Zhou et al., 1998). The setback viscosity of oat flour $(2254 \mathrm{cP})$ was found to be higher than that of corn flour $(1439 \mathrm{cP})$. The pasting temperatures of pure oat flour $\left(87.15^{\circ} \mathrm{C}\right)$ was significantly higher $(\mathrm{p}<0.05)$ as compared to the durum wheat semolina flour $(85.5$ $\left.{ }^{\circ} \mathrm{C}\right)$, corn flour $\left(76.75^{\circ} \mathrm{C}\right)$ and wheat semolina-oat flour blends, except for the variant prepared with 1:2 ratio of semolina and oat flour $\left(87.25^{\circ} \mathrm{C}\right)$. The increased values of the pasting temperature of oat flour may be due to the formation of the amylose-lipid complex, which delays the swelling of the starch granule, as the complex does not begin to dissociate until the temperature exceeds $85^{\circ} \mathrm{C} 9$ (Wang and White, 1994).

\section{Cooking quality}

One of the most important qualitative factors influencing the overall quality of pasta is cooking performance. Good quality pasta should preserve its shape during cooking and increase in volume with minimal material losses (Cleary and Brennan, 2006). The cooking time is an important factor for the quality of pasta products like vermicelli. The optimum cooking time is achieved when the centre of the vermicelli is fully hydrated. The effect of different percentages of oat flour on the cooking time of vermicelli samples is reported in Table 5.

The results showed that the cooking time varied from 335 to 675 seconds. It could be observed that the vermicelli prepared with a with higher amount of oat flour had a longer cooking time. Among the vermicelli samples, the shortest cooking time was observed for durum wheat-based vermicelli, while the longest was observed for the vermicelli incorporating $75 \%$ oat flour. The cooking time of all the oatsemolina based vermicelli were significantly $(\mathrm{p}<0.05)$ higher than the durum wheat based vermicelli. These observations are in agreement with Majzoobi et al. (2014) and Pilli et al. (2013), who reported an extension of the optimum cooking time with the increased level of oat flour in noodle samples. The gelatinization of the starch present determines the cooking time of vermicelli. The lipids in the oat flour 
might have interacted with starch and delayed the gelatinization process because it is well known that starch can interact with lipids to form starch-lipid complexes. The amylose-lipid complex prevents water entry into the granule, which may increase the cooking time ((Pilli et al., 2013). $\beta$-glucan could also be responsible for the stabilization of granular structures during heating, which could have resulted in prolonging the cooking time (Pilli et al., 2013).

Table 5. Cooking characteristics of vermicelli with different ratios of wheat semolina and oat flour*.

\begin{tabular}{cccccc}
\hline $\begin{array}{c}\text { Sample } \\
\text { Code }\end{array}$ & $\begin{array}{c}\text { Cooking } \\
\text { Time } \\
\text { (seconds) }\end{array}$ & $\begin{array}{c}\text { Cooking } \\
\text { Loss } \\
(\boldsymbol{\%})\end{array}$ & $\begin{array}{c}\text { Cooked } \\
\text { Weight } \\
(\mathbf{g})\end{array}$ & $\begin{array}{c}\text { Water Holding } \\
\text { Capacity (\%) }\end{array}$ & $\begin{array}{c}\text { Swelling Index } \\
(\boldsymbol{\%})\end{array}$ \\
\hline $\mathbf{C}$ & $335 \pm 3.61^{\mathrm{a}}$ & $2.42 \pm 0.23^{\mathrm{a}}$ & $78.00 \pm 1.61^{\mathrm{a}}$ & $121.09 \pm 0.58^{\mathrm{a}}$ & $1.80 \pm 0.12^{\mathrm{a}}$ \\
$\mathbf{T}_{\mathbf{1}}$ & $480 \pm 4.04^{\mathrm{e}}$ & $6.28 \pm 0.25^{\mathrm{d}}$ & $93.45 \pm 0.68^{\mathrm{c}}$ & $152.61 \pm 0.95^{\mathrm{e}}$ & $2.87 \pm 0.05^{\mathrm{bc}}$ \\
$\mathbf{T}_{\mathbf{2}}$ & $600 \pm 2.08^{\mathrm{g}}$ & $7.37 \pm 0.05^{\mathrm{e}}$ & $105.54 \pm 1.27^{\mathrm{d}}$ & $187.74 \pm 0.26^{\mathrm{g}}$ & $3.61 \pm 0.02^{\mathrm{d}}$ \\
$\mathbf{T}_{\mathbf{3}}$ & $675 \pm 3.00^{\mathrm{h}}$ & $7.56 \pm 0.07^{\mathrm{e}}$ & $122.60 \pm 1.73^{\mathrm{e}}$ & $214.88 \pm 0.01^{\mathrm{h}}$ & $3.62 \pm 0.13^{\mathrm{d}}$ \\
$\mathbf{T}_{\mathbf{4}}$ & $435 \pm 5.13^{\mathrm{c}}$ & $5.69 \pm 0.15^{\mathrm{c}}$ & $86.17 \pm 1.02^{\mathrm{bc}}$ & $140.49 \pm 0.40^{\mathrm{c}}$ & $2.69 \pm 0.10^{\mathrm{b}}$ \\
$\mathbf{T}_{\mathbf{5}}$ & $497 \pm 5.69^{\mathrm{f}}$ & $6.49 \pm 0.09^{\mathrm{d}}$ & $99.01 \pm 1.02^{\mathrm{f}}$ & $163.04 \pm 0.61^{\mathrm{f}}$ & $3.18 \pm 0.11^{\mathrm{c}}$ \\
$\mathbf{T}_{\mathbf{6}}$ & $421 \pm 3.21^{\mathrm{b}}$ & $3.18 \pm 0.01^{\mathrm{b}}$ & $82.02 \pm 0.99^{\mathrm{ab}}$ & $132.58 \pm 0.69^{\mathrm{b}}$ & $2.64 \pm 0.15^{\mathrm{b}}$ \\
$\mathbf{T}_{\mathbf{7}}$ & $465 \pm 1.53^{\mathrm{d}}$ & $6.31 \pm 0.10^{\mathrm{d}}$ & $89.16 \pm 0.52^{\mathrm{g}}$ & $149.09 \pm 0.42^{\mathrm{d}}$ & $2.85 \pm 0.09^{\mathrm{b}}$ \\
\hline
\end{tabular}

LSD value ( $\mathrm{p}<0.05)$ is equal to 10.809 for cooking time, 3.512 for cooked weight, 0.675 for water holding capacity and 0.384 for swelling index.

*Corn flour was added at the $15 \%$ rate of the mix of wheat semolina and oat flour. $\mathrm{C}, \mathrm{T}_{1}-\mathrm{T}_{7}$ : Same as in Table 1.

Each value is expressed as mean $\pm \mathrm{SE}$ ( $\mathrm{n}$ is equal to 3 )

Values followed by the different letter in the same column are significantly different $(\mathrm{p}<0.05)$

Cooking loss means the particles that diffuse out of the vermicelli into the cooking medium during the cooking process. Cooking loss also impacts the surface characteristics of the noodles (Shobha et al., 2015). Shobha et al. (2015) also reported that the higher the cooking loss, the stickier the vermicelli surface; hence cooking loss is undesirable because of the high starch content in the cooking medium and the vermicelli's low cooking tolerance. Higher oat flour addition caused significantly $(\mathrm{p}<0.05)$ higher cooking losses as compared to the samples that contained no oat flour (Table 5). Aydin and Gocmen (2011) reported higher cooking losses in oat-based vermicelli, which were attributed to the disruption of the protein-starch matrix and the subsequent expulsion of water. Oat flour additions to wheat flour formulations impart a softer, stickier and less elastic texture to vermicelli, due to the lack of gluten-forming proteins that provide structure and viscoelasticity (Majzoobi et al., 2014). The cooking quality of oat-based vermicelli is compromised by susceptibility to breakage (Majzoobi et al., 2014). Similar results were reported by Pilli et al. (2013) who evaluated the cooking quality of oat flour-based spaghetti by determining the dried residue and total organic matter, 
which could be due to the leaching out of water-soluble components in the oat flour, like $\beta$-glucan and soluble proteins e.g. albumins (Majzoobi et al., 2014).

The water holding capacity (WHC) of oat-semolina based vermicelli is shown in Table 5; it varied from 121.09 to $214.88 \%$. Among the vermicelli samples, the highest water holding capacity value was found for the vermicelli incorporating 75 $\%$ oat flour, and the lowest was found for the durum wheat-based vermicelli. The Swelling Index of oat-semolina based vermicelli varied from 1.80 to $3.62 \%$. The water holding capacity and the swelling index values of the oat flour supplemented vermicelli increased significantly $(p<0.05)$ with the level of oat flour. This may be due to the presence of $\beta$-glucan fibre in oat flour. Cleary and Brennan (2006) also reported an increase of the swelling index in pasta samples fortified with $\beta$-glucan fibre. Therefore, increased water absorption might be related to the higher amount of hydroxyl groups in fibre as compared to semolina, resulting in more interactions with water through hydrogen bonds (Majzoobi et al., 2014). Similar results were obtained by Pilli et al. (2013), who reported that spaghetti samples based on soft wheat flour showed a lower water uptake than samples supplemented with 15 and $30 \%$ oat flour. Moreover, in point of volume increase (\%), the cooked vermicelli prepared by substitution of wheat semolina flour with $15 \%$ corn flour, showed significant $(\mathrm{p}<0.05)$ increase (Table 5).

\section{Sensory attributes of vermicelli}

The average values for the sensory attributes of the different vermicelli samples are shown in Table 6. The appearance score was the highest for the durum wheat-based vermicelli samples, and the lowest for the vermicelli incorporating $75 \%$ oat flour. When increasing the amount of oat flour in vermicelli, the appearance score decreased slightly $(\mathrm{p}>0.05)$. But all the vermicelli samples prepared with oat flour were at least 'slightly liked' by the panellists. Aydin and Gocmen (2011) reported that the prime reason for disliking oat flour vermicelli was their darker colour. Starch mouth coating is defined as the degree to which sample mixes with saliva to form starchy and pasty slurry that coats the mouth surfaces during mastication. The lowest value of the starch mouth coating was observed for the durum wheat-based vermicelli samples, and the highest for vermicelli samples with maximum $(75 \%)$ oat flour (Table 6). The starch mouth coating of the oat-semolina based vermicelli varied significantly $(p<0.05)$ from the durum wheat-based vermicelli samples.

This suggests that the oat flour component may mix with saliva and form pasty slurry in the mouth more readily than the durum wheat flour component. In contrast with other cereal starches, which primarily exude amylose, oat flour exudes both amylose and amylopectin (Wang and White, 1994), which could be a reason for the highest starch mouth coating associated with vermicelli containing oat flour. The sensory scores of cooked vermicelli revealed that the lowest value of bulkiness and grittiness was reported for the durum wheat-based vermicelli samples, while the highest was found in the samples with maximum $(75 \%)$ oat flour level. In general, the addition of oat flour increased the bulkiness and grittiness score of vermicelli samples. This could be due to the presence of high levels of $\beta$-glucan fibre. (Pilli et al., 2013). 


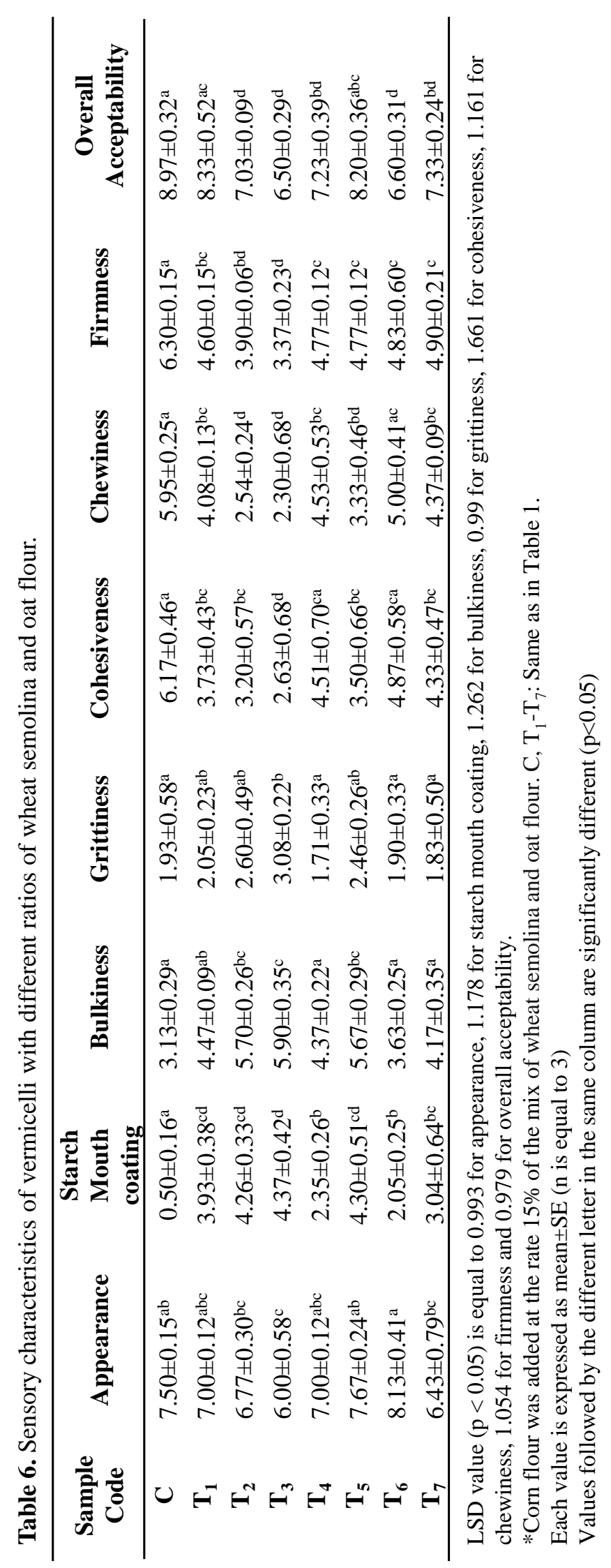


The highest value of chewiness, cohesiveness and firmness was reported for the durum wheat-based vermicelli samples, and the lowest for the vermicelli samples with the highest $(75 \%)$ amount of oat flour. The vermicelli samples containing at least $40 \%$ oat flour varied significantly $(\mathrm{p}<0.05)$ in these three sensory attributes from the durum wheat-based vermicelli. The cohesiveness of pasta products like spaghetti and noodles were reported to possess a positive relationship with the gluten content of flour (Majzoobi et al., 2014). The higher values of firmness in the durum wheat-based vermicelli could be due to the high gluten content of wheat semolina, as gluten has been reported to be responsible for the firmness of vermicelli (Yadav et al., 2014). Among the vermicelli samples, the highest overall acceptability score was found for the durum wheat-based vermicelli, and the lowest score was attributed to the samples incorporating $75 \%$ oat flour. The overall acceptability score of the vermicelli samples containing at least $50 \%$ oat flour, found to be similar $(p>0.05)$ to the pure durum wheat-based vermicelli.

\section{Conclusions}

The addition of oat flour to vermicelli increased protein, fat, ash and $\beta$-glucan contents. Pasting properties of flour combinations varied significantly $(\mathrm{p}<0.05)$. The cooking quality parameters; cooking time, cooking losses, cooked weight, water holding capacity and swelling index of all the oat-semolina based vermicelli were significantly $(p<0.05)$ higher than durum wheat-based vermicelli. Increased levels of oat flour slightly decreased $(\mathrm{p}<0.05)$ sensory acceptability. Scores for sensory attributes like starch mouth coating, bulkiness and grittiness was highest for oat-semolina based vermicelli, as compared to durum wheat-based samples. Cohesiveness, chewiness and firmness values were highest for durum wheat-based vermicelli as compared to oat flour added vermicelli. Among the vermicelli samples containing oat flour, addition up to $50 \%$ oat flour in vermicelli imparted organoleptic changes in vermicelli that were considered acceptable by the sensory panel members as well as adequate cooking quality. Therefore, replacement of $50 \%$ of wheat semolina by oat flour produced vermicelli with acceptable sensory parameters and cooking quality.

\section{Acknowledgments}

This research received no specific grant from any funding agency in the public, commercial or not-for-profit sectors but the researchers are thankful to Director, ICAR-NDRI Karnal for providing lab infrastructure and facilities to conduct the experiments.

\section{References}

AACC. 2000. Approved Methods of American Association of Cereal Chemists. $10^{\text {th }}$ ed St. Paul, MN, USA.

AOAC. 2000. Official methods of analysis $16^{\text {th }}$ ed. Association of Official Analytical Chemists Washington, USA. 
Aydin, E., Gocmen, D. 2011. Cooking quality and sensorial properties of noodle supplemented with oat flour. Food Science and Biotechnology, 20, 507-511.

BIS. 1993. Bureau of Indian Standards. IS SP 1485 (1993). Macaroni, spaghetti, vermicelli and Egg noodles - specification, Manak Bhawan, New Delhi.

Brown, A. 2014. Flours and Flour Mixtures. In: Understanding food: principles and preparation, 372. Cengage Learning Publishers, Stamford, U.S.A.

Chandla, N.K., Saxena, D.C., Singh, S. 2017. Processing and evaluation of heat moisture treated (HMT) amaranth starch noodles; an inclusive comparison with corn starch noodles. Journal of Cereal Science, 75, 306-313.

Choi, I., Han, O.K., Chun, J., Kang, C.S., Kim, K.H., Kim, Y.K., Cheong, Y.K., Park, T.I., Choi, J.S., Kim, K.J. 2012. Hydration and pasting properties of oat (Avena sativa) flour. Preventive Nutrition and Food Science, 17, 87.

Cleary, L., Brennan, C. 2006. The influence of a $(1 \rightarrow 3)(1 \rightarrow 4)-\beta$-d-glucan rich fraction from barley on the physico-chemical properties and in vitro reducing sugars release of durum wheat pasta. International Journal of Food Science and Technology, 41, 910918.

Deshpande, H.W., Poshadri, A. 2011. Physical and sensory characteristics of extruded snacks prepared from Foxtail millet based composite flours. International Food Research Journal, 18, 751-756.

Gulvady, A.A., Brown, R.C., Jenna, A.B. 2013. Nutritional comparison of oats and other commonly consumed whole grains. In: Oat Nutrition and Technology. Chu, Y. (Ed.). John Wiley \& Sons, U.S., 222.

Havrlentova, M., Petruláková, Z., Burgárová, A., Gago, F., Hlinková, A., Šturdík, E. 2011. Cereal $\beta$-glucans and their significance for the preparation of functional foods-a review. Czech Journal of Food Sciences, 29, 1-14.

Kaur, G., Sharma S., Dar, B.N. 2010. Effect of different cereal bran incorporations on pasting properties of wheat semolina. Advance Journal of Food Science, 32, 212-216.

Majzoobi, M., Layegh, M.M.B., Farahnaky, A. 2014. Inclusion of oat flour in the formulation of regular salted dried noodles and its effects on dough and noodle properties. Journal Food Processing and Preservation, 38, 48-58.

Manley, D. 2011. Meals, grits, flours and starches (other than wheat). In: Manley's technology of biscuits, crackers and cookies, 135. Woodhead Publishers, Cambridge, U.K, 135 .

Nadiha, M.N., Fazilah, A., Bhat, R., Karim, A.A. 2010. Comparative susceptibilities of sago, potato and corn starches to alkali treatment. Food Chemistry, 121, 1053-1059.

Oomah, B.D. 1983. Baking and related properties of wheat-oat composite flours. Cereal Chemistry, 60, 220-225.

Palacios-Fonseca, A.J., Vazquez-Ramos, C., Rodríguez-García, M.E. 2009. Physicochemical characterizing of industrial and traditional nixtamalized corn flours. Journal of Food Engineering, 93, 45-51.

Pilli, T., Derossi, A., Severini, C. 2013. Cooking quality characterisation of 'spaghetti' based on soft wheat flour enriched with oat flour. International Journal of Food Science and Technology, 48, 2348-2355.

Rayas-Duarte, P., Mock, C.M., Satterlee, L.D. 1996. Quality of spaghetti containing buckwheat, amaranth, and lupin flours. Cereal Chemistry, 73, 381-387. 
Bhise, S., Kaur, A., Aggarwal, P. 2015. Development of protein enriched noodles using texturized defatted meal from sunflower, flaxseed and soybean. Journal of Food Science and Technology, 52, 5882-5889.

Salehifar, M., Shahedi, M. 2010. Effects of oat flour on dough rheology, texture and organoleptic properties of taftoon bread. Journal of Agricultural Science and Technology, 9, 227-234.

Sandhu, K.S., Singh, N., Malhi, N.S. 2007. Some properties of corn grains and their flours I: Physicochemical, functional and chapati-making properties of flours. Food Chemistry, 101, 938-946.

Shobha, D., Vijayalakshmi, D., Asha, K.J. 2015. Evaluation of maize flour incorporated vermicelli for nutritional, sensory and storage quality. Journal of Food Science and Technology, 52, 7173-7181.

Shogren, R.L., Hareland, G.A., Wu, Y.V. 2006. Sensory evaluation and composition of spaghetti fortified with soy flour. Journal of Food Science, 71, S428-432.

Sowbhagya, C.M., Zakiuddin Ali, S. 2001. Vermicelli noodles and their quality assessment. Journal of Food Science and Technology, 38, 423-432.

Sudha, M.L., Rajeswari, G., Venkateswara Rao, G. 2012. Effect of wheat and oat brans on the dough rheological and quality characteristics of instant vermicelli. Journal of Texture Studies, 43, 195-202.

Sudha, M.L., Vetrimani, R., Leelavathi, K. 2007. Influence of fibre from different cereals on the rheological characteristics of wheat flour dough and on biscuit quality. Food Chemistry, 100, 1365-1370.

Wang, L.Z., White, P.J. 1994. Functional properties of oat starches and relationships among functional and structural characteristics. Cereal Chemistry, 71, 451-458.

Yadav, B.S., Yadav, R.B., Kumari, M., Khatkar, B.S. 2014. Studies on suitability of wheat flour blends with sweet potato, colocasia and water chestnut flours for noodle making. LWT-Food Science and Technology, 57, 352-358.

Zhou M., Robards K., Glennie-Holmes M., Helliwell S. 1998. Structure and pasting properties of oat starch. Cereal Chemistry, 75, 273-281. 